\title{
Tibiotalocalcanean Fusion by Retrograde Sign Nail: An Amazing Solution for Old Ankle Fracture
}

\author{
Jibananda Halder ${ }^{1, *}$, Md Zulfiqur Ali², Nahid Sultana ${ }^{3}$ \\ ${ }^{1}$ Department of Orthopaedic Surgery, National Institute of Traumatology \& Orthopaedic Rehabilitation (NITOR), Dhaka, Bangladesh \\ ${ }^{2}$ Department of Orthopaedic Surgery, Shaheed Mansur Ali Medical College, Sirajganj, Bangladesh \\ ${ }^{3}$ Department of Gynaecology \& Obstetrics, Rajshahi Medical College Hospital, Rajshahi, Bangladesh
}

\section{Email address:}

dhiman1270@gmail.com (J. Halder)

*Corresponding author

\section{To cite this article:}

Jibananda Halder, Md Zulfiqur Ali, Nahid Sultana. Tibiotalocalcanean Fusion by Retrograde Sign Nail: An Amazing Solution for Old Ankle Fracture. Journal of Surgery. Vol. 8, No. 5, 2020, pp. 166-170. doi: 10.11648/j.js.20200805.15

Received: June 20, 2020; Accepted: July 13, 2020; Published: October 26, 2020

\begin{abstract}
Background: Old ankle fracture is the most challenging problem in whole over the world. Still it is an unsolved problem in many countries like Bangladesh. For ankle fracture so many under-privileged people in our country usually take traditional treatment in the village and suffer from severe pain during walking. Sometimes they want to commit suicide due to pain. Earlier the tibiotalocalcanean fusion was done by only steinman pin, then by conventional interlocki nail. But retrograde SIGN nail is the amazing solution to relief pain in old ankle fracture. Aim of the study: The aim of this study was to assess the outcomes of tibiotalocalcanean fusion (Arthrodesis) by retrograde SIGN nail. Methods: It was a prospective case series of patients with old ankle fractures treated with the SIGN nail conducted during the period from 2017 to 2019 at NITOR, Dhaka of Bangladesh. A total of 35 patients with old ankle fractures were operated using the SIGN nail among which 29 patients came for follow up at 6,16 and 18, 48 weeks. So finally 29 patients were finalized as the study population. Result: As per AOFAS score in pre-operative stage, condition of all the participants were 'poor' but at post-operative stage AOFAS score was found 'Excellent' in 10.34\% $(\mathrm{n}=3)$, 'Good' in 34.48\% $(\mathrm{n}=10)$ 'Fair' in $20.69 \%(\mathrm{n}=6)$ and 'Poor' in $23.48 \%(\mathrm{n}=10)$ participants respectively. Besides this, according to the VAS score in the pre-operative stage $3.45 \%$ mild $(n=1), 6.90 \%$ moderate $(n=2)$, and $89.65 \%$ severe $(\mathrm{n}=26)$ cases patients. Besides this, in post-operative stage $48.24 \%$ mild $(\mathrm{n}=14), 44.83 \%$ moderate $(\mathrm{n}=13)$, and $6.90 \%$ severe $(\mathrm{n}=2)$ cases. Conclusion: This implant may be a good alternative in developing countries. The findings of this study may be helpful in further similar studies and in the treatment procedure.
\end{abstract}

Keywords: Old Ankle Fracture, Retrograde SIGN Nailing, Tibiotalocalcanean Fusion, Arthrodesis

\section{Introduction}

Old ankle fracture is the most challenging problem in whole over the world. Still it is an unsolved problem in many countries like Bangladesh. For ankle fracture so many underprivileged people in our country usually take traditional treatment in the village and suffer in severe pain during walking. Sometimes the patient want to commit suicide due to pain. Tibiotalocalcaneal arthrodesis is indicated in patients with complex hindfoot deformity, failed ankle arthroplasty and failed ankle joint arthrodesis with subsequent subtalar arthritis [1]. It has been shown to be an effective treatment option for pain relief and correction of hindfoot malalignment in such subjects [2-5]. Besides other cases tibiotalocalcaneal arthrodesis is better for the treatment old ankle fracture. Many alternative fixations such as crossed cancellous screws, angle bladed plates, external frames, and intramedullary nails combined with bone graft have been reported for performing TTCA [1-4]. In many cases, tibiotalocalcaneal arthrodesis (TTCA) acts as a salvage procedure and alternative to amputation in non-braceable neuropathic deformities, failed ankle arthrodesis, failed total ankle arthroplasty, talar osteonecrosis, and severe ankle and subtalar arthritis $[5,6]$. On the other hand, SIGN is 
structurally intramedullary rods, fin nails and screws are designed to provide fixation of tibial, femoral and humeral fractures while they heal. During the fixation the surgeon must select the type and size that best meets the patient's requirements for close adaptation and firm seating with adequate support. Ankle fractures have increased in incidence over the last 30 years, affecting one in every 800 people each year, typically young active males and geriatric osteoporotic females, and accounting for $9 \%$ of all fractures $[7,8]$ Management of the fracture itself ranges from non-operative treatment with immediate weight bearing to surgery and 12 weeks of non-weight bearing. Care of the patient includes greater considerations such as medical optimization, rehabilitation, and safe return to work and activity. Now a day tibiotalocalcanean fusion by retrograde SIGN nail is considered as a gold slandered procedure for such management. The general goals of fracture management are anatomic reduction of the fracture and protection of the soft tissue envelope. Stable fractures, where the alignment of the ankle joint is preserved, rarely need surgery. Unstable fractures typically require closed reduction or open reduction and internal fixation, depending on the patient's co-morbidities and pre-injury functional status. There is an increasing trend toward operative management of unstable ankle fractures, but historically good long-term outcomes have been well documented with non-operative management [9].

\section{Objective}

The general objective of this study was to assess the outcomes of tibiotalocalcanean fusion (Arthrodesis) by retrograde SIGN nail.

\section{Methodology \& Materials}

It was a prospective case series of patients with old ankle fractures treated with the SIGN nail conducted during the period from 2017 to 2019 at NITOR, Dhaka of Bangladesh. A total of 35 patients with old ankle fractures were operated using the SIGN nail of whom 29 patients came for follow up at 6,16 and 18, 48 weeks. So finally 29 patients were finalized as the study population. According to the inclusion criteria of the study patients with old ankle fracture $(>3$ months), fresh injuries, closed fractures, adult patients (1560 ), patients of both sexes, patients with trauma of any severity or any kind and fracture nonunion were included in the study. On the other hand, according to the exclusion criteria of the study, patients with open fracture, fractures of young adult, pathological fracture, patient unfit for major surgical intervention, patient with deformity of at least one lower limb, polio, joint contractures and amputees and patient with underlying uncontrolled comorbid condition or Diabetes mellitus of hypertension were excluded from the study. All operations were done under spinal anaesthesia with tourniquet control. Patients was placed in a supine position and affected limb is a bit higher than other limb. After the patient was anaesthesized, the affected limb skin is washed, cleaned with soap and water, dried, and then painted with $10 \%$ povidone iodine solution from knee to foot. Then the patient was draped with sterile sheets exposing only the leg. The insertion point is identified by marker. A one inch vertical incision is made on the meeting point. Then by inner blade incision was made deep up to bone (clcaneum). Then by awl opening is made for sign remur. From lower to larger diameter of sign remer was used in parallel to tibia. I should confirm by feeling remer movement within tibia. Both proximal and distal fragment was reamed through the awl opening and fracture side accordingly with appropriate size of reamer. Progressively reaming was done in $1 \mathrm{~mm}$ increasing to diameter of the nail. Then appropriate nail should be less long than tibial tuberosity chosen. Proximal screw that should be within calcaneum was inserted. Then distal at least one screw should be inserted. Actually no need of reduction, only reaming is sufficient for fusion of ankle. Postoperatively limb was elevated on a pillow keeping the knee in slight flexion. The patient started isometric quadriceps exercise after 24 hours of operation. The patient was allowed to move out of bed when patient felt comfort, having crutches and without bearing weight on the operated limb. Stitches were removed on the $14^{\text {th }}$ postoperative day. Knee range of motion exercises were started as early as possible when patients feel comfort. Postoperatively, prophylactic antibiotics were given routinely for 2 weeks in all cases. Patient was discharged with the advice to walk on crutch bearing no weight on the affected side for 6 weeks and then to report to the OPD.

\section{Results}

In this study finally 29 subjects were finalized as the study population. Among them $74.29 \%(n=26)$ were male and $25.71 \%(n=9)$ were female. So male were dominating in number in this study. In the evaluation of the AOFAS (American Orthopaedic Association of Foot \& Ankle Score) questionnaire in the pre-operative stage, condition of all the participants were 'poor'. On the other hand, at the postoperative period, we noted improved scores. At postoperative stage AOFAS score was found 'Excellent' in $10.34 \%(n=3)$, 'Good' in 34.48\% $(n=10)$ 'Fair' in $20.69 \%$ $(n=6)$ and 'Poor' in $23.48 \%(n=10)$ participants respectively. Besides this, according to the VAS (Visual Analogue Score) questionnaire in the pre-operative stage among 29 participants we found, $3.45 \%$ mild $(\mathrm{n}=1), 6.90 \%$ moderate $(n=2)$, and $89.65 \%$ severe $(n=26)$ cases. Besides this, according to the VAS score in the post-operative stage among 29 participants we found, 48.24\% mild ( $n=14)$, $44.83 \%$ moderate $(n=13)$, and $6.90 \%$ severe $(n=2)$ cases. The rate of satisfaction with the procedure was $93 \%$ (In total 27 out of 29 patients). For making a clear concept about diagnosis in both the pre-operative and post-operative stages, we herewith added some diagnostic report (X-ray) of one of our participants. 


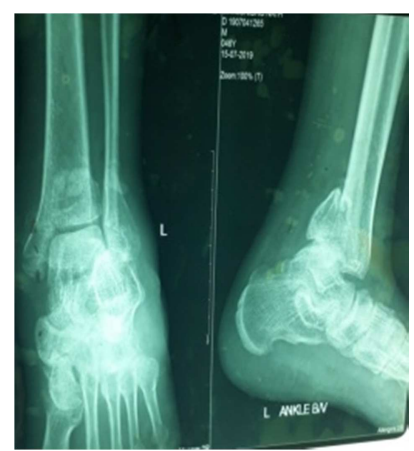

Figure 1. Pre-operative report of a sample participant.

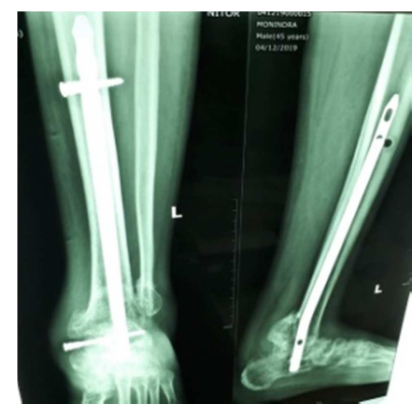

Figure 2. F/U after 18 weeks of a sample participant.
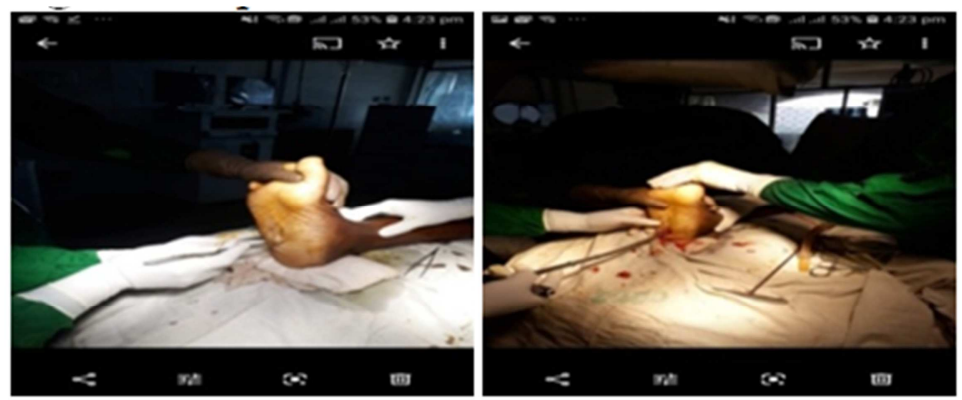

Figure 4. Operation in NITOR.
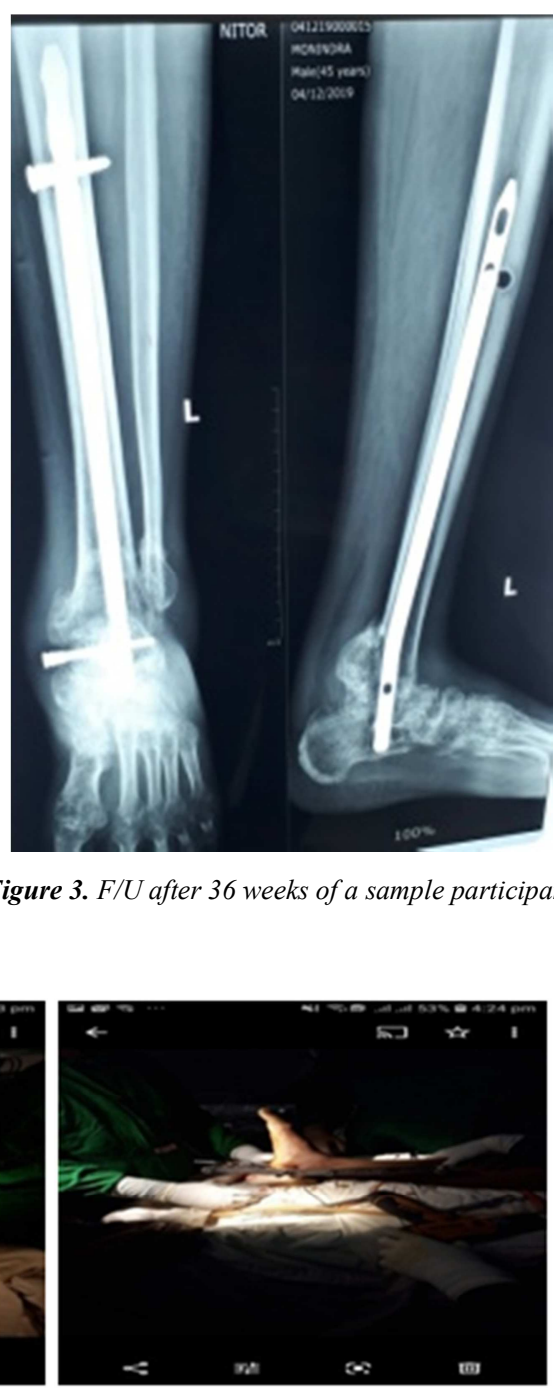

Figure 3. F/U after 36 weeks of a sample participant.
Table 1. AOFAS score distribution among participants $(N=29)$.

\begin{tabular}{lll}
\hline Score & $\mathbf{n}$ & $\mathbf{\%}$ \\
\hline Excellent & 3 & 10.34 \\
Good & 10 & 34.48 \\
Fair & 6 & 20.69 \\
Poor & 10 & 34.48 \\
\hline
\end{tabular}

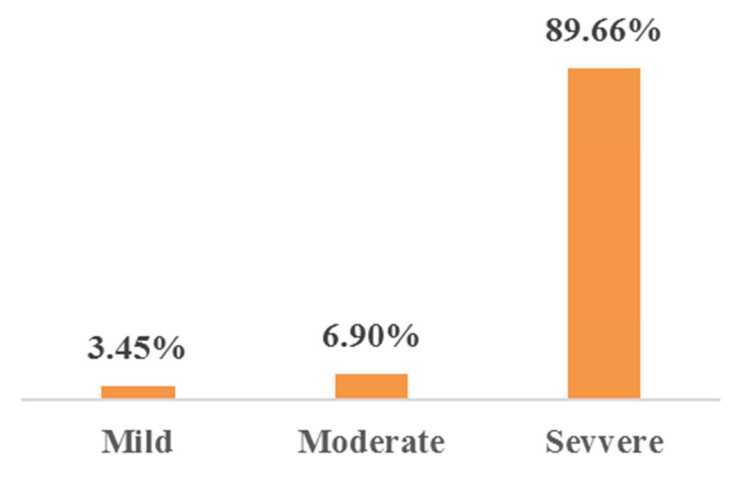

Figure 5. Pre-operative VAS score distribution among participants $(N=29)$.

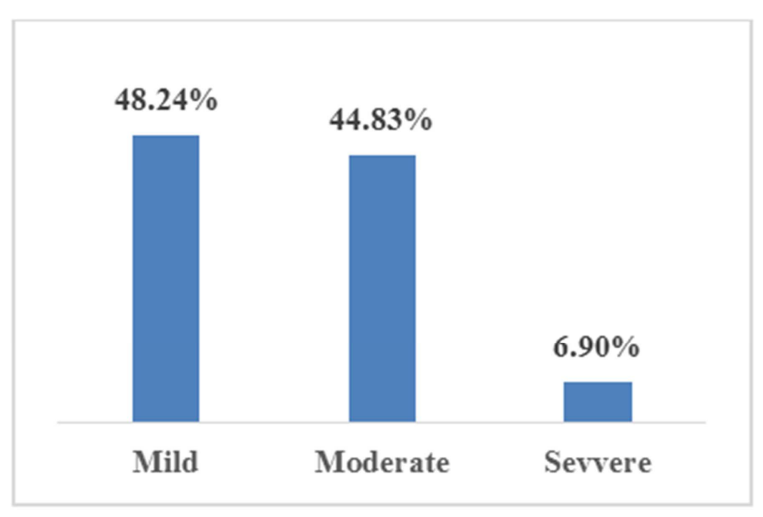

Figure 6. Post-operative VAS score distribution among participants $(N=29)$.

\section{Discussion}

The treatment of patients with arthritis, pain and deformity of the ankle and subtalar junction is still a challenge and is extremely difficult to get excellent results. The main surgical goals of the tibiotalocalcaneal arthrodesis are to reduce pain and promote a stable and plantigrade foot with good function 
for deambulation. In the last decade, a number of studies reporting complications and high rates of nonunion (4-24\%). The aim of this study was to assess the outcomes of tibiotalocalcanean fusion (Arthrodesis) by retrograde SIGN nail. In our intervention after the patient was anaesthesized, affected limb skin is washed, cleaned with soap and water, dried, and then painted with $10 \%$ povidone iodine solution from knee to foot. Then the patient was draped with sterile sheets exposing only the leg. The insertion point is identified by marker. A one inch vertical incision is made on the meeting point. Then by inner blade incision was made deep up to bone. Then by awl opening is made for sign remur. From lower to larger diameter of sign remer is used in parallel to tibia. I should confirm by feeling remer movement within tibia. All the above measures were taken in our study to avoid any complication. In some international studies that were reported. Some irritation around the tip of the nail was seen in our patients but there were no fractures. We generally remove proximal screws after 3 to 4 months. This will reduce irritation and stress- related problems around the tip of the nail and allow compression of the ankle arthrodesis. Prominent proximal locking screws can result in irritation and ulceration and also can induce stress fractures [10]. Damage to the neurovascular bundle at the insertion point of the nail is a known complication in retrograde nailing [11]. In some study they claimed, the overall complication rate of using a nail in TTCA reportedly ranges from $4 \%$ [12] to $59 \%$ [13]. Complications include complications of wound healing, superficial and deep infection, pseudoarthrosis, neurovascular damage, malalignment, stress reactions, fracture and persistent pain. Additionally, lateral plantar neurovascular damage resulting in a permanent but tolerable sensory loss on the plantar aspect of the foot has been reported with a straight nail [14]. In our study in the evaluation of the AOFAS (American Orthopaedic Association of Foot \& Ankle Score) questionnaire in the preoperative stage, condition of all the participants were 'poor'. On the other hand, at the post-operative period, we noted improved scores. At post-operative stage AOFAS score was found 'Excellent' in 10.34\% ( $\mathrm{n}=3)$, 'Good' in 34.48\% $(\mathrm{n}=10)$ 'Fair' in $20.69 \% \quad(n=6)$ and 'Poor' in $23.48 \% \quad(n=10)$ participants respectively. On the other hand, according to the VAS score in the post-operative stage among 29 participants we found, $48.24 \%$ mild $(n=14), 44.83 \%$ moderate $(n=13)$, and $6.90 \%$ severe $(n=2)$ cases. The rate of satisfaction with the procedure in our study was $93 \%$. It was in total 27 out of 29 patients. This satisfaction rate is very good comparing other similar treatment method. Here we can consider some findings of some international studies. After arthrodesis, most patients are satisfied with the relief of pain. The limited hindfoot motion makes it difficult to walk on uneven surfaces which can be helped by the use of rocker bottom shoe with a solid-ankle cushioned-heel [15] Under conditions of normal daily living while wearing shoes, all patients function well after arthrodesis [16] Ankle arthrodesis can be done using either of the following materials: cancellous screws, plates and screws, external fixator, and intramedullary nails. We chose retrograde intramedullary nailing technique because retrograde intramedullary nailing provides a load-sharing fixation device with superior biomechanical properties [17] Ankle arthrodesis using intramedullary nails has shown good results in the past [18].

Limitations of the Study

This was a single centered study with a small sized sample. So the findings of this study may not reflect the exact scenario of the whole country.

\section{Conclusion and Recommendations}

This implant may be a good alternative in developing countries. The findings of this study may be helpful in further similar studies and in the treatment procedure. For getting more specific findings we would like to recommend for conducting more studies regarding the same issue with larger sized sample.

\section{References}

[1] Bennett Budnar VM, Hepple S, Harries WG, Livingstone JA, Winson I. Tibiotalocalcaneal arthrodesis with a curved, interlocking, intramedullary nail. Foot Ankle Int, 2010, 31: 1085-1092.

[2] Boer R, Mader K, Pennig D, Verheyen CC. Tibiotalocalcaneal arthrodesis using a reamed retrograde locking nail. Clin Orthop Relat Res, 2007, 463: 151-156.

[3] Carrier DA, Harris CM. Ankle arthrodesis with vertical Steinmann's pins in rheumatoid arthritis. Clin Orthop Relat Res, 1991, 268: 10-14.

[4] Haaker R, Kohja EY, Wojciechowski M, Gruber G. Tibiotalo-calcaneal arthrodesis by a retrograde intramedullary nail. Ortop Traumatol Rehabil, 2010, 12: 245-249.

[5] Bennett GL, Cameron B, Njus G, Saunders M, Kay DB (2005) Tibiotalocalcaneal arthrodesis: a biomechanical assessment of stability. Foot Ankle Int 26 (7): 530-536.

[6] Jehan S, Shakeel M, Bing AJ, Hill SO (2011) The success of tibiotalocalcaneal arthrodesis with intramedullary nailing--a systematic review of the literature. Acta Orthop Belg 77 (5): 644-651.

[7] Rockwood CA, Green DP, Bucholz RW. Rockwood and Green's fractures in adults. 7th ed. Philadelphia, PA: Wolters Kluwer Health/Lippincott Williams \& Wilkins. 2010.

[8] Donken CC, Al-Khateeb H, Verhofstad MH, van Laarhoven CJ. Surgical versus conservative interventions for treating ankle fractures in adults. Cochrane Database Syst Rev. 2012; 8: CD008470.

[9] Wei SY, Okereke E, Winiarsky R, Lotke PA. Nonoperatively treated displaced bimalleolar and trimalleolar fractures: a 20 year follow-up. Foot Ankle Int. 1999; 20 (7): 404-407.

[10] Hammett R, Hepple S, Forster B, Winson I. Tibiotalocalcaneal (hindfoot) arthrodesis by retrograde intramedullary nailing using a curved locking nail: the results of 52 procedures. Foot Ankle Int. 2005; 26: 810815. 
[11] Anderson T, Linder L, Rydholm U, Montgomery F, Besjakov J, Carlsson A. Tibio-talocalcaneal arthrodesis as a primary procedure using a retrograde intramedullary nail: a retrospective study of 26 patients with rheumatoid arthritis. Acta Orthop. 2005; 76: 580-587.

[12] Anderson T, Linder L, Rydholm U, Montgomery F, Besjakov J, Carlsson A. Tibio-talocalcaneal arthrodesis as a primary procedure using a retrograde arthritis. Acta Orthop, 2005, 76: 580-587.

[13] Mears DC, Gordon RG, Kann SE, Kann JN. Ankle arthrodesis with an anterior tension plate. Clin Orthop Relat Res, 1991, 268: 70-77.

[14] Thordarson DB, Chang D. Stress fractures and tibial cortical hypertrophy after tibiotalocalcaneal arthrodesis with an intramedullary nail. Foot Ankle Int, 1999, 20: 497-500.
[15] Pickering RM. Campbell's Operative Orthopedics. 11th ed., Vol. 1, Ch. 3: 163. Mosby Elsevier publishers; 2008.

[16] Mazur JM, Schwartz E, Simon SR. Ankle arthrodesis. Longterm follow-up with gait analysis. J Bone Joint Surg Am 1979; 61: 964-75.

[17] Veselý R, Procházka V, Visna P, Valentová J, Savolt J. Tibiotalocalcaneal arthrodesis using a retrograde nail locked in the sagittal plane. Acta Chir Orthop Traumatol Cech 2008; 75: 129-33.

[18] Moore TJ, Prince R, Pochatko D, Smith JW, Fleming S. Retrograde intramedullary nailing for ankle arthrodesis. Foot Ankle Int 1995; 16: 433-6. 